\title{
云南杨梅碳、氮、磷化学计量特征
}

\author{
苏凯文 $^{1}$ 陈路红 ${ }^{1}$ 郑 伟 ${ }^{1}$ 潘 瑶 ${ }^{2}$ 尹华军 ${ }^{3}$ 巩合德 ${ }^{*}$
}

${ }^{1}$ 西南林业大学生态旅游学院, 昆明 $650224{ }^{2}$ 西南林业大学亚太森林组织昆明培训中心, 昆明 $650224{ }^{3}$ 中国科学院成都生物研究所, 成都 610041

摘 要 碳 $(\mathrm{C})$ 、氮 $(\mathrm{N})$ 、磷 $(\mathrm{P})$ 在植物生长和各种生理调节机能中发挥着重要作用。为研究云南灌丛生态系统C、N、P含量之 间的关系以及植物生物量、土壤 $\mathrm{C} 、 \mathrm{~N} 、 \mathrm{P}$ 含量与植物 $\mathrm{C} 、 \mathrm{~N} 、 \mathrm{P}$ 含量的相互影响, 该研究采用样地调查的方法, 在云南省云南 杨梅(Myrica nana)灌从主要分布区设立了 29 个样地, 通过测量样地中云南杨梅灌从C、N、P含量, 系统分析了云南杨梅 $\mathrm{C} 、 \mathrm{~N}$ 、 $\mathrm{P}$ 的计量规律。结果显示: 1)研究区域云南杨梅根、茎、叶的C、N、P含量的平均值分别是 $45.94 \% 、 0.54 \% 、 0.03 \%, 46.32 \%$ 、 $0.58 \% 、 0.03 \%$ 和 $49.05 \% 、 1.70 \% 、 0.06 \%$ (干质量), 其中叶的C、N、P含量均显著高于茎和根。在根中C: $\mathrm{N}: \mathrm{P}$ 为 1 531:18:1, 在 茎中C:N:P为1 544:19:1, 而在叶中C:N:P为818:10:1, 反映了云南杨梅不同部位元素计量不同的分配关系; 2)云南杨梅叶片中C 含量和 $\mathrm{N}: \mathrm{P}$ 值随生物量的增加而降低, 但只有叶片 C含量与生物量的相关关系极显著, 而 $\mathrm{N}: \mathrm{P}$ 值与生物量的相关关系不显著。 叶片中 $\mathrm{N}$ 含量和 $\mathrm{P}$ 含量随生物量的增加而升高, 其中 $\mathrm{P}$ 含量与生物量的相关关系显著, $\mathrm{N}$ 含量与生物量的相关关系不显著。云南 杨梅叶的 $\mathrm{N}: \mathrm{P}$ (34.2)明显大于 8 , 说明 $\mathrm{P}$ 是云南杨梅生长的限制因素。3)根的C、N、P含量与土壤中的 $\mathrm{P}$ 含量都有显著的相关性, 其中 $\mathrm{N} 、 \mathrm{P}$ 为极显著正相关, $\mathrm{C}$ 为显著负相关; 茎的 $\mathrm{C}$ 含量与土壤的 $\mathrm{C} 、 \mathrm{~N} 、 \mathrm{P}$ 含量都显著负相关, 且 $\mathrm{N} 、 \mathrm{P}$ 含量的相关性极显著, 而 茎的 $\mathrm{P}$ 含量与土壤中的 $\mathrm{P}$ 含量极显著正相关; 叶的 $\mathrm{P}$ 含量与土壤的 $\mathrm{C} 、 \mathrm{~N} 、 \mathrm{P}$ 含量都极显著正相关, 叶的 $\mathrm{C}$ 含量则与土壤的 $\mathrm{P}$ 含量 极显著负相关。该研究结果可为西南高原灌从生态系统的研究提供数据支持。

关键词 云南杨梅; 碳; 氮; 磷; 元素计量; 生物量; 土壤

引用格式: 苏凯文, 陈路红, 郑伟, 潘瑶, 尹华军, 巩合德 (2017). 云南杨梅碳、氮、磷化学计量特征. 植物生态学报, 41, 136-146. doi: $10.17521 /$ cjpe.2016.0026

\section{Carbon, nitrogen and phosphorus stoichiometry of Myrica nana in Yunnan, China}

\section{SU Kai-Wen ${ }^{1}$, CHEN Lu-Hong ${ }^{1}$, ZHENG Wei ${ }^{1}$, PAN Yao ${ }^{2}$, YIN Hua-Jun ${ }^{3}$, and GONG He-De ${ }^{1 *}$}

${ }^{1}$ Ecotourism Faculty, Southwest Forestry University, Kunming 650224, China; ${ }^{2}$ Asia-Pacific Network For Sustainable Forest Management And Rehabilitation Kunming Training Center, Kunming 650224, China; and ${ }^{3}$ Chengdu Institute of Biology, Chinese Academy of Science, Chengdu 610041, China

\section{Abstract}

Aims Carbon (C), nitrogen (N) and phosphorus (P) play important roles in plant growth and physiological functions. We aimed at exploring the intrinsic relationships of $\mathrm{C}, \mathrm{N}$ and $\mathrm{P}$ in Myrica nana-a common shrub in Yunnan Province-as well as their relationships with pant biomass and soil nutrients.

Methods We measured the concentration of C, N and P of M. nana from 29 sites for their magnitudes and correlations with soil nutrients.

Important findings 1) The arithmetic mean value of $\mathrm{C}, \mathrm{N}$ and $\mathrm{P}$ concentration in the roots, stems and leaves of M. nana was 45.94\%, 0.54\%, 0.03\%, and 46.32\%, 0.58\%, 0.03\%, and 49.05\%, 1.70\%, 0.06\%, respectively. C, N and $\mathrm{P}$ concentrations in the leaves were significantly higher than those in the roots and the stems. The C:N:P in roots, stems and leaves was 1 531:18:1, 1 544:19:1, and 818:10:1, respectively. 2) The C concentration and N:P in leaves of $M$. nana decreased with the increase of biomass of $M$. nana; the leaf $C$ concentration was significantly correlated with biomass ( $p<0.01$ ), while the correlation between $\mathrm{N}$ :P and biomass was not significant $(p>0.05)$. The leaf $\mathrm{N}$ increased with the increase of plant biomass, the $\mathrm{P}$ was significantly correlated with biomass $(p<$ $0.05)$, but the correlation between $\mathrm{N}$ concentration and biomass was not significant $(p>0.05)$. $\mathrm{N}$ :P in leaves was 34.2, suggesting that plant growth was limited by P. 3) $\mathrm{C}, \mathrm{N}$ and $\mathrm{P}$ concentration in the roots were significantly correlated with soil $\mathrm{P}(p<0.05)$, with $\mathrm{N}$, P concentrations correlated with soil $\mathrm{P}$ positively $(p<0.01)$ and $\mathrm{C}$ negatively $(p<0.05)$. C concentration in the stems was significantly and negatively correlated with soil C, N, with significant correlation with $\mathrm{C}, \mathrm{N}$, and $\mathrm{P}$ concentration $(p<0.01)$. $\mathrm{P}$ concentration in the stems was significantly and 
positively correlated with soil P concentration $(p<0.01)$, while leaf P significantly and positively correlated with soil C, N and P ( $p<0.01)$; leaf C concentration was significantly and negatively correlated with soil $\mathrm{P}(p<0.01)$.

Key words Myrica nana; carbon; nitrogen; phosphorus; stoichiometry; biomass; soil

Citation: Su KW, Chen LH, Zheng W, Pan Y, Yin HJ, Gong HD (2017). Carbon, nitrogen and phosphorus stoichiometry of Myrica nana in Yunnan, China. Chinese Journal of Plant Ecology, 41, 136-146. doi: 10.17521/cjpe.2016.0026

生态化学计量学结合了热力学第一定律、生物 进化的自然选择原理和分子生物学中心法则, 包括 了生态学和化学计量学的基本方法(王绍强和于贵 瑞, 2008), 使得生物学科不同层次(分子、细胞、有 机体、种群、生态系统和全球尺度)的研究理论能够 有机地统一起来(曾德慧和陈广生, 2005), 为研究生 态系统能量和化学元素 (以碳 $(\mathrm{C}) 、$ 氮 $(\mathrm{N})$ 、磷 $(\mathrm{P})$ 为主) 平衡以及生态结构与功能提供了一种新的手段(洪 江涛等, 2013), 并与现今的热点一一全球碳循环和 全球气候变化紧密地结合起来(Elser et al., 2000a, 2010)。植物生长过程中, C、N、P 是构建植物体和 驱动代谢过程最重要的元素, 碳水化合物、木质素、 纤维素、酶、核苷酸等的代谢都与这 3 种元素有关 (Elser et al., 2010; van de Waal et al., 2010)。研究发 现, 不同地带植物叶 $\mathrm{N}: \mathrm{P}$ 不同(张文彦等, 2010; 任书 杰等, 2012), 生长季植物叶 $\mathrm{C}: \mathrm{N} 、 \mathrm{C}: \mathrm{P}$ 和 $\mathrm{N}: \mathrm{P}$ 变化趋势 不同(牛得草等, 2013), 植物叶 $\mathrm{C}: \mathrm{N}$ 和 $\mathrm{N}: \mathrm{P}$ 与草原退 化程度相关(银晓瑞等, 2010), 群落植物物种多样性 和生物量与叶 C: $\mathrm{N}$ 和 $\mathrm{N}: \mathrm{P}$ 回归关系显著(颉洪涛等, 2016), 事实上, 生态化学计量特征影响着植物生长 率和生物量(Elser et al., 2000b; Ågren, 2008; 严正兵 等, 2013; 颉洪涛等, 2016)。研究这些元素的计量学 特征对探索植物生长、生态系统功能发挥的机制具 有极为重要的作用(闵帮国等, 2015)。近年来, 植物 生态化学计量学取得了丰硕的研究成果, 诸多假说 和研究见诸刊物, 如植物 N:P 的营养限制理论 (Koerselman \& Meuleman, 1996), 植物叶片 N:P地理 分布模式的物种组成假说(Vitousek \& Farrington, 1997; Wright, 2001), 草本植物和环境因子的关系 等。不同学者对不同生态系统的C、N、P化学计量 特征做了大量研究, 韩文轩等(2009)研究了北京及 周边地区植物叶的C、N、P计量特征，系统分析了 北京周边358种不同生长型植物叶的C、N、P计量规 律; 邵学新等(2013)对杭州湾潮滩湿地3种优势植物 的C、 $N 、 P$ 含量做了动态分析。然而目前我国C、 $N$ 、 P计量研究主要集中于草原地区和黄土高原(Zheng
\& Shangguan, 2007; He et al., 2008), 对地处云贵高 原、地形复杂、气候多变的云南灌丛生态系统尚缺 乏有关的系统分析和报道。在全球变暖的趋势下， 灌丛分布范围有所扩大(Sturm et al., 2001), 在由生 物入侵导致植被演替引起的北半球局部区域碳储量 变化中, 灌丛生态系统能发挥巨大作用。灌从植物 通过光合作用和蒸腾作用吸收大气中的 $\mathrm{CO}_{2}$ 、获取 土壤中的水分和矿物质元素, 参加整个生物圈的生 物地球化学循环(Ehleringer \& Field, 1993)。加强灌 从植物C、N、P元素计量特征及其空间格局的研究, 是准确评估区域生态系统初级生产力和地球化学循 环及其全球变化响应机制的基础, 所以针对灌从系 统的研究势必成为新的热点(Jackson et al., 2002)。 我国是世界上灌从分布面积最广的国家，灌从面积 约 $2 \times 10^{8} \mathrm{hm}^{2}$, 占我国陆地总面积的 $1 / 5$ 左右, 约为 中国现存森林面积的2倍(刘国华等, 2003; 巩合德 等, 2012), 在中国研究灌从生态系统的生态化学计 量特征有天然的优势。云南灌从系统的代表植物云 南杨梅(Myrica nana) 是中国的特有种, 为杨梅科杨 梅属常绿灌木, 其树高在0.5-2.0 m之间, 雌雄异株, 2-3月开花, 6-7月果实成熟(中国科学院中国植物志 编辑委员会, 1979), 根部有放线菌共生, 起生物固 氮作用, 对生态环境有积极作用。云南杨梅分布区 域性强, 仅分布在我国云南、贵州、西藏和四川等 省区的部分地区, 能在黄壤、黄棕壤、暗红壤和红 壤中生存, 海拔1900-2500 m内生长最好, 是云南 杨梅的最适生区。因其自身的代表性和广布性, 云 南杨梅的研究对保护云南乃至西南地区的灌从系统 意义重大。

区域尺度上植物的 $\mathrm{N}$ 和 $\mathrm{P}$ 特征能反映植物特性 及其对环境条件的长期响应与适应(侯学显, 1982)。 大多数陆生植物的生长经常受 $N 、 P$ 限制或二者的共 同限制(Koerselman \& Meuleman, 1996; Venterink et al., 2003; Harpole et al., 2011)。叶片作为植物的主要 光合器官, 其 $\mathrm{N}: \mathrm{P}$ 的大小经常被用来表明植物生长 受到哪种元素的限制作用, 但是这种限制关系会随 
着外界环境的改变而变化(Koerselman \& Meuleman, 1996; Aerts \& Chapin, 2000; Güsewell, 2004; He et al., 2008; von Oheimb et al., 2010)。相同区域的植物 也可能因为外界环境与内在属性的区别, 其受限制 的营养元素也不同(王晶苑等, 2011)。由于植物的 N 限制和 $\mathrm{P}$ 限制对植物生长的控制, 生态化学计量特 征影响着植物生物量变化(Aerts \& Beltman, 2003; Güsewell Beltman., 2005), 土壤N含量和P含量的多 少又在一定程度上调节着植物的生态元素计量, 同 时, 植物生物量是生态系统获取能量的集中体现, 能够表征植物的生长状态。所以本研究通过实测云 南14个县区29个样地的云南杨梅样品和对应土壤样 品, 收集云南杨梅的生物量数据、C、N、P数据和 土壤的 $C 、 N 、 P$ 数据, 以阐明以下几个问题: 1)云南 杨梅内在的C、N、P计量特征; 2)云南杨梅叶片 C、
$\mathrm{N} 、 \mathrm{P}$ 含量与其生物量的关系及云南杨梅生长的限制 元素; 3)云南杨梅 $C 、 N 、 P$ 含量与土壤 $C 、 N 、 P$ 含量 之间的关系, 以期为我国西南地区的灌从植物元素 计量学研究和中国陆地生态系统的碳咜量、碳交换 评估提供基础科学数据, 为保护当地的灌丛生态系 统提供理论依据。

\section{1 材料和方法}

\section{1 野外调查和元素测量}

在云南杨梅分布比较广的 14 个县区, 选取 29 个 典型分布区建立灌从类型样地(表1)。每个样地按照 分布特征设计 3 个典型的 $5 \mathrm{~m} \times 5 \mathrm{~m}$ 的样方, 并在每 个样方内随机选取 1 个 $1 \mathrm{~m} \times 1 \mathrm{~m}$ 的样方, 测量该样 方内所有云南杨梅的生物量。测量时按照根、茎、 叶分别用电子天平称质量, 每个器官选取 $150 \mathrm{~g}$ 以上

表1 云南29个云南杨梅标准样地的相关信息

Table 1 Characteristics of the 29 study sites of Myrica nana shrub in Yunnan Province

\begin{tabular}{|c|c|c|c|c|}
\hline 样地编号 Site number & 样地地点 Site location & 纬度 Latitude $(\mathrm{N})$ & 经度 Longitude (E) & 海拔 Altitude (m) \\
\hline YN002 & 云南省姚安县 Yao’an, Yunnan & $25.52^{\circ}$ & $101.40^{\circ}$ & 2220.6 \\
\hline YN003 & 云南省姚安县 Yao’an, Yunnan & $25.49^{\circ}$ & $101.31^{\circ}$ & 2623.1 \\
\hline YN004 & 云南省姚安县 Yao’an, Yunnan & $25.50^{\circ}$ & $101.15^{\circ}$ & 2093.3 \\
\hline YN006 & 云南省大姚县 Dayao, Yunnan & $25.66^{\circ}$ & $101.15^{\circ}$ & 2258.6 \\
\hline YN010 & 云南省大姚县 Dayao, Yunnan & $25.71^{\circ}$ & $101.48^{\circ}$ & 2120.4 \\
\hline YN011 & 云南省大姚县 Dayao, Yunnan & $25.91^{\circ}$ & $101.23^{\circ}$ & 2396.0 \\
\hline YN013 & 云南省牟定县 Mouding, Yunnan & $25.45^{\circ}$ & $101.46^{\circ}$ & 2037.9 \\
\hline YN016 & 云南省牟定县 Mouding, Yunnan & $25.44^{\circ}$ & $101.53^{\circ}$ & 2145.2 \\
\hline YN017 & 云南省牟定县 Mouding, Yunnan & $25.45^{\circ}$ & $101.63^{\circ}$ & 2245.0 \\
\hline YN018 & 云南省南华县 Nanhua, Yunnan & $25.33^{\circ}$ & $101.03^{\circ}$ & 2567.2 \\
\hline YN019 & 云南省南华县 Nanhua, Yunnan & $25.17^{\circ}$ & $101.06^{\circ}$ & 2392.4 \\
\hline YN020 & 云南省南华县 Nanhua, Yunnan & $25.32^{\circ}$ & $101.26^{\circ}$ & 2148.2 \\
\hline YN022 & 云南省禄丰县 Lufeng, Yunnan & $25.31^{\circ}$ & $102.12^{\circ}$ & 2113.1 \\
\hline YN024 & 云南省禄丰县 Lufeng, Yunnan & $25.31^{\circ}$ & $101.90^{\circ}$ & 2199.1 \\
\hline YN025 & 云南省禄丰县 Lufeng, Yunnan & $25.32^{\circ}$ & $101.87^{\circ}$ & 2272.3 \\
\hline YN026 & 云南省安宁县 Anning, Yunnan & $24.86^{\circ}$ & $102.45^{\circ}$ & 2043.8 \\
\hline YN027 & 云南省安宁县 Anning, Yunnan & $24.82^{\circ}$ & $102.42^{\circ}$ & 2123.4 \\
\hline YN028 & 云南省安宁县 Anning, Yunnan & $24.85^{\circ}$ & $102.39^{\circ}$ & 1950.0 \\
\hline YN029 & 云南省昆明市 Kunming, Yunnan & $25.14^{\circ}$ & $102.61^{\circ}$ & 2183.4 \\
\hline YN030 & 云南省嵩明县 Songming, Yunnan & $25.41^{\circ}$ & $103.04^{\circ}$ & 2084.8 \\
\hline YN038 & 云南省昆明市 Kunming, Yunnan & $25.22^{\circ}$ & $102.66^{\circ}$ & 2137.5 \\
\hline YN039 & 云南省富民县 Fumin, Yunnan & $25.23^{\circ}$ & $102.42^{\circ}$ & 2086.0 \\
\hline YN040 & 云南省富民县 Fumin, Yunnan & $25.28^{\circ}$ & $102.63^{\circ}$ & 2214.7 \\
\hline YN041 & 云南省寻甸县 Xundian, Yunnan & $25.54^{\circ}$ & $103.39^{\circ}$ & 2060.9 \\
\hline YN044 & 云南省寻甸县 Xundian, Yunnan & $25.52^{\circ}$ & $103.38^{\circ}$ & 2008.0 \\
\hline YN050 & 云南省会泽县 Huize, Yunnan & $26.47^{\circ}$ & $103.46^{\circ}$ & 2040.0 \\
\hline YN052 & 云南省会泽县 Huize, Yunnan & $26.50^{\circ}$ & $103.45^{\circ}$ & 2010.0 \\
\hline YN058 & 云南省师宗县 Shizong, Yunnan & $24.91^{\circ}$ & $103.87^{\circ}$ & 2156.0 \\
\hline YN068 & 云南省砚山县 Yanshan, Yunnan & $23.77^{\circ}$ & $104.68^{\circ}$ & 1656.0 \\
\hline
\end{tabular}


的材料带回实验室, 于 $70{ }^{\circ} \mathrm{C}$ 的烘箱中烘烤 $48 \mathrm{~h}$ 至恒 质量。根、茎、叶样品分别在粉碎机中粉碎后再次 烘干至恒质量, 分别测量其C、N、P含量 $(\%)$ 。C和 $\mathrm{N}$ 含量用C/N元素分析仪(2400II CHNS/O, PerkinElmer, Boston, USA) 测量; 将样品粉末采用 $\mathrm{H}_{2} \mathrm{O}_{2}$ $\mathrm{H}_{2} \mathrm{SO}_{4}$ 凯氏(Kjedahl)法消解, 然后用钼蓝比色法测 量P的含量。

\section{2 数据处理方法}

植物不同部位C、N、P含量的内部分配关系用 Pearson相关关系分析, 采用 $t$ 检验比较植物不同部 位C、N、P含量差异, 根据Pearson相关性分析分析 植物叶片 $\mathrm{N} 、 \mathrm{P}$ 与生物量的相关性, 并对植物 $\mathrm{C} 、 \mathrm{~N}$ 、 $\mathrm{P}$ 含量与土壤C、N、P含量做回归分析。

\section{2 结果}

\section{1 云南杨梅C、N、P含量及其相关性}

云南杨梅根的 $\mathrm{C} 、 \mathrm{~N} 、 \mathrm{P}$ 含量变化范围分别为 40.96\%-47.83\%、0.38\%-0.82\%、0.01\%-0.11\%（表

$2)$, 平均值分别是 $45.94 \% 、 0.54 \% 、 0.03 \%$; 茎的C、
$\mathrm{N} 、 \mathrm{P}$ 含量变化范围为 $43.89 \%-47.74 \% 、 0.40 \%-0.93 \%$ 、 $0.01 \%-0.09 \%$, 平均值分别为 $46.32 \% 、 0.58 \% 、 0.03 \%$; 叶的C、N、P含量变化范围分别为 $43.97 \%-51.03 \%$ 、 $029 \%-2.15 \% 、 0.03 \%-0.14 \%$, 平均值分别为 $49.05 \%$ 、 $1.70 \% 、 0.06 \%$ (表2)。在根中C: $\mathrm{N}: \mathrm{P}$ 约为1 531:18:1, 在茎中 $C: N: P$ 约为 1 544:19:1, 而在叶中 $C: N: P$ 约为 818:10:1, 在根中 $\mathrm{C}: \mathrm{N} 、 \mathrm{C}: \mathrm{P}$ 和 $\mathrm{N}: \mathrm{P}$ 的质量比值约为 86.6、 2559.8 和29.6, 在茎中 $: \mathrm{N} 、 \mathrm{C}: \mathrm{P}$ 和 $\mathrm{N}: \mathrm{P}$ 的质量 比值约为82.2、2 656.2 和31.9, 叶中C: $N 、 C: P$ 和 $N: P$ 的质量比值约为30.4、1 012.9和34.2 (表3), 这表明 营养元素在云南杨梅执行不同功能的部位之间具有 明显不同的分配规律(元素计量特征)。

植物不同部位 $t$ 检验分析表明，云南杨梅根和 茎的C含量存在显著差异 $(p<0.05)$, 叶和根、茎的C 含量都存在极显著差异 $(p<0.01)$; 根和茎的 $\mathrm{N}$ 含量 差异不显著 $(p>0.05)$, 叶和根、茎的 $\mathrm{N}$ 含量都存在极 显著差异 $(p<0.01)$; 根和茎的 $\mathrm{P}$ 含量差异不显著 $(p>$ $0.05)$, 叶和根、茎的 $\mathrm{P}$ 含量存在极显著差异 $(p<$ $0.01)$, 叶的 $\mathrm{C} 、 \mathrm{~N} 、 \mathrm{P}$ 含量均高于其他部位。

表2 云南杨梅C、N、P含量统计特征

Table 2 Statistics of carbon (C), nitrogen (N), and phosphorus (P) in Myrica nana

\begin{tabular}{|c|c|c|c|c|c|c|c|c|c|}
\hline & 变量 & Variable & 数量 & Number & 平均值 Mean (\%) & 中值 Median (\%) & 标偏差 Standard deviation & 最大值 Maximum (\%) & 最小值 Minimum (\%) \\
\hline \multirow[t]{3}{*}{$\mathrm{C}$} & & 根 Root & & 84 & 45.94 & 46.03 & 1.05 & 47.83 & 40.96 \\
\hline & & 茎 Shoot & & 83 & 46.32 & 46.48 & 0.69 & 47.74 & 43.89 \\
\hline & & 叶 Leaf & & 84 & 49.05 & 49.25 & 1.03 & 51.03 & 43.97 \\
\hline \multirow{3}{*}{\multicolumn{2}{|c|}{$\mathrm{N}$}} & 根 Root & & 84 & 0.54 & 0.54 & 0.86 & 0.82 & 0.38 \\
\hline & & 茎 Shoot & & 84 & 0.58 & 0.56 & 0.12 & 0.93 & 0.40 \\
\hline & & 叶 Leaf & & 84 & 1.70 & 1.73 & 0.23 & 2.15 & 0.29 \\
\hline \multirow{3}{*}{\multicolumn{2}{|c|}{$\mathrm{P}$}} & 根 Root & & 84 & 0.03 & 0.02 & 0.03 & 0.11 & 0.01 \\
\hline & & 茎 Shoot & & 84 & 0.03 & 0.02 & 0.02 & 0.09 & 0.01 \\
\hline & & 叶 Leaf & & 84 & 0.06 & 0.05 & 0.02 & 0.14 & 0.03 \\
\hline
\end{tabular}

表3 云南杨梅C、N、P化学计量统计特征

Table 3 Stoichiometric characteristic of carbon (C), nitrogen (N), and phosphorus (P) in Myrica nana

\begin{tabular}{|c|c|c|c|c|c|c|}
\hline 部位 Part & 变量 Variable & 数量 Number & 平均值 Mean & 最大值 Maximum & 最小值 Minimum & 标准偏差 Standard Deviation \\
\hline \multirow[t]{3}{*}{ 根 Root } & $\mathrm{C}: \mathrm{N}$ & 84 & 86.6 & 120.0 & 57.1 & 13.5 \\
\hline & $\mathrm{C}: \mathrm{P}$ & 84 & 2559.8 & 5189.6 & 419.7 & 1494.8 \\
\hline & $\mathrm{N}: \mathrm{P}$ & 84 & 29.6 & 70.0 & 5.1 & 17.1 \\
\hline \multirow[t]{3}{*}{ 茎 Stem } & $\mathrm{C}: \mathrm{N}$ & 83 & 82.2 & 116.3 & 49.9 & 14.5 \\
\hline & $\mathrm{C}: \mathrm{P}$ & 83 & 2656.2 & 7235.8 & 514.4 & 1515.5 \\
\hline & $\mathrm{N}: \mathrm{P}$ & 83 & 31.9 & 83.76 & 4.95 & 16.7 \\
\hline \multirow[t]{3}{*}{ 叶 Leaf } & $\mathrm{C}: \mathrm{N}$ & 84 & 30.4 & 153.9 & 23.1 & 14.1 \\
\hline & $\mathrm{C}: \mathrm{P}$ & 84 & 1012.9 & 1918.7 & 340.6 & 322.3 \\
\hline & $\mathrm{N}: \mathrm{P}$ & 84 & 34.2 & 64.6 & 9.1 & 9.8 \\
\hline
\end{tabular}


通过植物 C、N、P相关性分析(表4)可以看出: 1) 根中各元素相关性均不显著 $(p>0.05)$; 茎的C含量 和P含量显著负相关, 其他元素间相关性不显著 $(p>$ $0.05)$; 叶的 C含量和 $\mathrm{P}$ 含量极显著负相关 $(p<0.01)$, $\mathrm{N}$ 含量和 $\mathrm{P}$ 含量极显著正相关 $(p<0.01)$, 其他元素 间相关性不显著 $(p>0.05)$ 。2)在根茎之间, C含量、 $\mathrm{P}$ 含量极显著正相关 $(p<0.01), \mathrm{N}$ 含量没有显著的相 关性 $(p>0.05)$, 而根的 $\mathrm{N}$ 含量和茎的 C含量、根的 $\mathrm{P}$ 含量和茎的 C含量显著负相关 $(p<0.05)$, 根的 $\mathrm{N}$ 含 量和茎的 $\mathrm{P}$ 含量显著正相关 $(p<0.05)$, 其余元素间 相关性不显著; 在根和叶之间, C含量、P含量极显著 正相关 $(p<0.01)$, $\mathrm{N}$ 含量相关性不显著 $(p>0.05)$, 根 的 $\mathrm{C}$ 含量和叶的 $\mathrm{P}$ 含量、根的 $\mathrm{N}$ 含量和叶的 $\mathrm{C}$ 含量、 根的 $\mathrm{P}$ 含量和叶的 $\mathrm{C}$ 含量显著负相关 $(p<0.05)$, 根的 $\mathrm{N}$ 含量和叶的 $\mathrm{P}$ 含量极显著正相关 $(p<0.01)$, 其余 元素间相关性不显著 $(p>0.05)$; 在茎叶之间, C、 $\mathrm{P}$ 含量都极显著正相关 $(p<0.01)$, N含量显著正相关 $(p<0.05)$, 而茎的 $\mathrm{C}$ 含量和叶的 $\mathrm{P}$ 含量、茎的 $\mathrm{P}$ 含量 和叶的 C含量都极显著负相关 $(p<0.01)$, 其余元素 间相关性不显著 $(p>0.05)$ 。叶的 $\mathrm{C}$ 含量与 $\mathrm{P}$ 含量的负 相关性以及叶的 $\mathrm{N}$ 含量与 $\mathrm{P}$ 含量的正相关性是高等 陆生植物C、N、P元素计量的普遍规律(Sterner \& Elser, 2002), 体现了绿色植物在固C过程中养分(N、 P等)利用效率的权衡策略(Vitousek, 1982; Aerts \& Chapin, 2000; Diemer, 2004)。

\section{2 云南杨梅叶片 $\mathrm{C} 、 \mathrm{~N} 、 \mathrm{P}$ 含量及 $\mathrm{N}: \mathrm{P}$ 与生物量的 关系}

根据图1可看出云南杨梅叶片中C含量和 $\mathrm{N}: \mathrm{P}$ 随 生物量的增加而降低, 但只有叶片 $\mathrm{C}$ 含量与生物量 的相关关系极显著 $(p<0.01)$, 而 $\mathrm{N}: \mathrm{P}$ 与生物量的相
关关系不显著。叶片中 $\mathrm{N}$ 含量和 $\mathrm{P}$ 含量随生物量的增 加而升高, 其中 $\mathrm{P}$ 含量与生物量的相关关系显著 $(p<$ $0.05), \mathrm{N}$ 含量与生物量的相关关系不显著 $(p>0.05)$ 。

\section{3 云南杨梅 $C 、 N 、 P$ 含量与土壤的关系}

如图2所示, C含量在土壤表层 $(0-10 \mathrm{~cm})$ 最大, 随土层的加深而逐渐降低, 0-10 cm 和10-20 cm 土壤 中C含量降低幅度最大, 最小显著差异法 $(L S D)$ 进一 步分析显示, 0-10 cm、10-20 cm、20-30 cm 土壤C 含量显著高于其他土层 $(p<0.05)$, 且 3 个土层之间 也存在显著差异, 其他各层土壤 $\mathrm{C}$ 含量变化较为平 缓, 差异不显著 $(p>0.05)$ 。土壤 $\mathrm{N}$ 含量整体上随土层 深度加深而下降, 其中土层前 4 层各自与其他各层 差异显著 $(p<0.05), 50-70 \mathrm{~cm} 、 70-100 \mathrm{~cm}$ 土层差异 不显著 $(p>0.05)$ 。 $\mathrm{P}$ 含量随土层变化的差异不显著 $(p$ $>0.05)$, 整体上波动不大, 无明显规律, 只有在 50-70 cm 出现波动, 但与其他土层差异也不显著 $(p$ $>0.05$ )。这与潘鹏等(2014)对马尾松(Pinus massoniana) 天然林土壤 $\mathrm{C} 、 \mathrm{~N} 、 \mathrm{P}$ 含量的研究结果一致。

由于表层土 $(0-10 \mathrm{~cm})$ 的 $\mathrm{C} 、 \mathrm{~N} 、 \mathrm{P}$ 含量与植物活 动关系最为密切(潘军等, 2015), 故本文着重对表层 土的C、 $\mathrm{N} 、 \mathrm{P}$ 含量与云南杨梅 $\mathrm{C} 、 \mathrm{~N} 、 \mathrm{P}$ 含量进行分 析。通过分析云南杨梅根、茎、叶化学计量学特征 与土壤因子的关系, 可知根的 $\mathrm{C} 、 \mathrm{~N} 、 \mathrm{P}$ 含量与土壤 的 $\mathrm{P}$ 含量有显著的相关性, 其中 $\mathrm{N}$ 含量、 $\mathrm{P}$ 含量极显 著正相关 $(p<0.01)$, 回归系数分别为 $0.547 、 0.157, \mathrm{C}$ 含量则显著负相关 $(p<0.05)$, 回归系数为 -5.278 ; 茎的C含量与土壤的 $\mathrm{C} 、 \mathrm{~N} 、 \mathrm{P}$ 含量都显著或极显著 负相关 (C: $p<0.05 ; \mathrm{N} 、 \mathrm{P}: p<0.01)$, 回归系数分别 为 $-0.182 、-3.368 、-5.086$; 而茎的 $\mathrm{P}$ 含量与土壤的 $\mathrm{P}$ 含量极显著正相关 $(p<0.01)$, 回归系数为 0.182 ; 叶

表4 植物不同部位C、N、P含量的相关关系

Table 4 Relationship among carbon (C), nitrogen (N) and phosphorus (P) concentration in different parts of Myrica nana

\begin{tabular}{|c|c|c|c|c|c|c|c|c|c|c|}
\hline \multirow{2}{*}{$\begin{array}{l}\text { 部位 } \\
\text { Part }\end{array}$} & \multirow{2}{*}{$\begin{array}{l}\text { 项目 } \\
\text { Element }\end{array}$} & \multicolumn{3}{|c|}{ 根 Root } & \multicolumn{3}{|c|}{ 茎 Stem } & \multicolumn{3}{|c|}{ 叶 Leaf } \\
\hline & & $\mathrm{C}$ & $\mathrm{N}$ & $\mathrm{P}$ & $\mathrm{C}$ & $\mathrm{N}$ & $\mathrm{P}$ & $\mathrm{C}$ & $\mathrm{N}$ & $\mathrm{P}$ \\
\hline 根 & $\mathrm{C}$ & 1 & -0.025 & -0.020 & $0.43^{* *}$ & -0.03 & -0.10 & $0.43^{* *}$ & -0.09 & $-0.27^{*}$ \\
\hline \multirow[t]{2}{*}{ Root } & $\mathrm{N}$ & & 1 & 0.080 & $-0.27^{*}$ & 0.20 & $0.25^{*}$ & $-0.23^{*}$ & 0.20 & $0.42^{* *}$ \\
\hline & $\mathrm{P}$ & & & 1 & $-0.28^{*}$ & -0.13 & $0.58^{* *}$ & $-0.27^{*}$ & 0.05 & $0.42^{* *}$ \\
\hline 茎 & $\mathrm{C}$ & & & & 1 & 0.14 & $-0.53^{* *}$ & $0.65^{* *}$ & 0.01 & $-0.57^{* *}$ \\
\hline \multirow[t]{2}{*}{ Stem } & $\mathrm{N}$ & & & & & 1 & 0.18 & -0.11 & $0.25^{*}$ & 0.06 \\
\hline & $\mathrm{P}$ & & & & & & 1 & $-0.45^{* *}$ & 0.05 & $0.49^{* *}$ \\
\hline 叶 & $\mathrm{C}$ & & & & & & & 1 & 0.18 & $-0.47^{* *}$ \\
\hline \multirow[t]{2}{*}{ Leaf } & $\mathrm{N}$ & & & & & & & & 1 & $0.43^{* *}$ \\
\hline & $\mathrm{P}$ & & & & & & & & & 1 \\
\hline
\end{tabular}

$*, p<0.05 ; * *, p<0.01$ 。

www.plant-ecology.com 

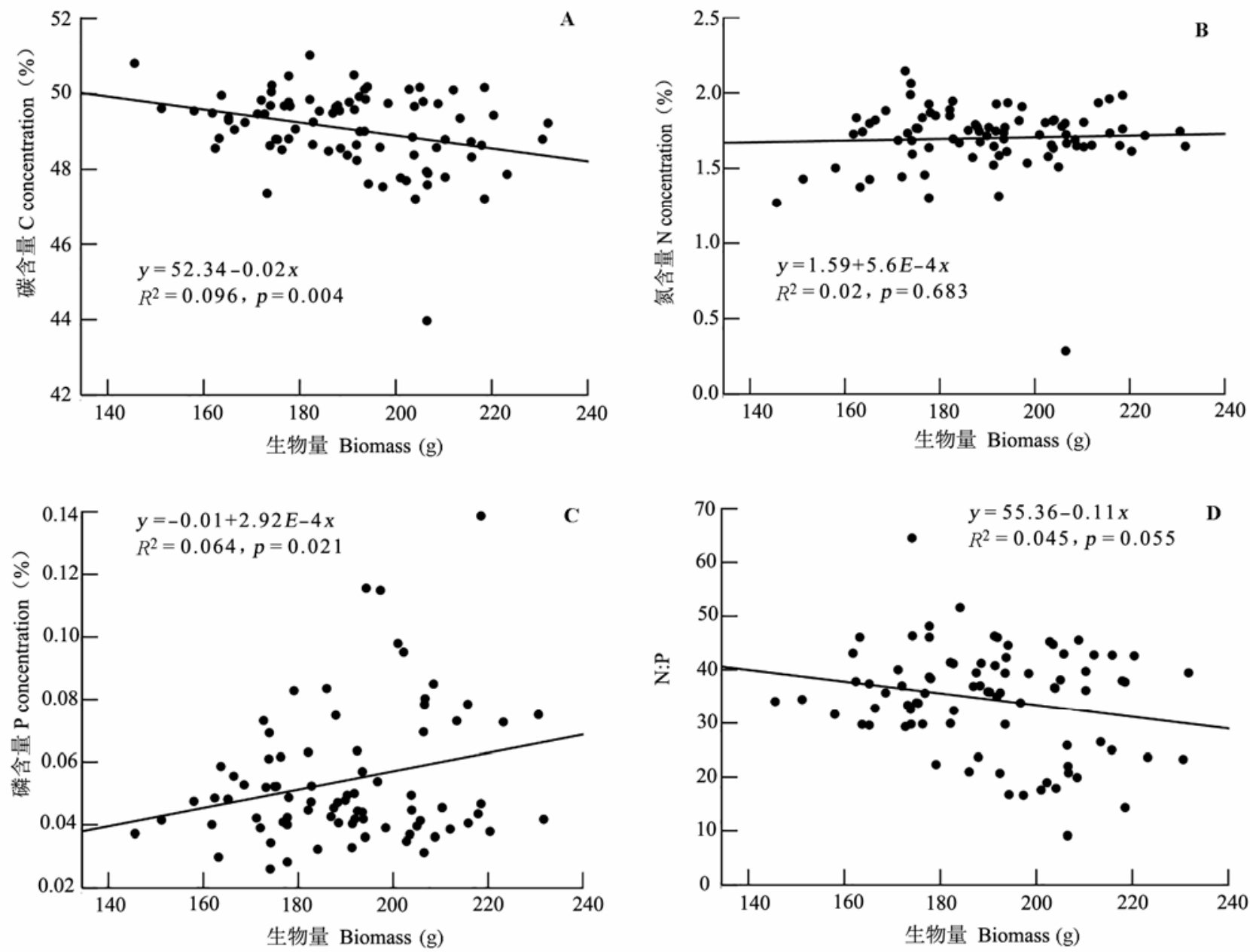

图1 云南杨梅生物量与叶片碳 $(A)$ 、氮 $(B)$ 、磷含量 $(\mathbf{C})$ 及 $N: P(D)$ 的关系。

Fig. 1 Relationship between biomass and C (A), N (B), and P (C) concentrations, N:P (D) of leaf of Myrica nana.

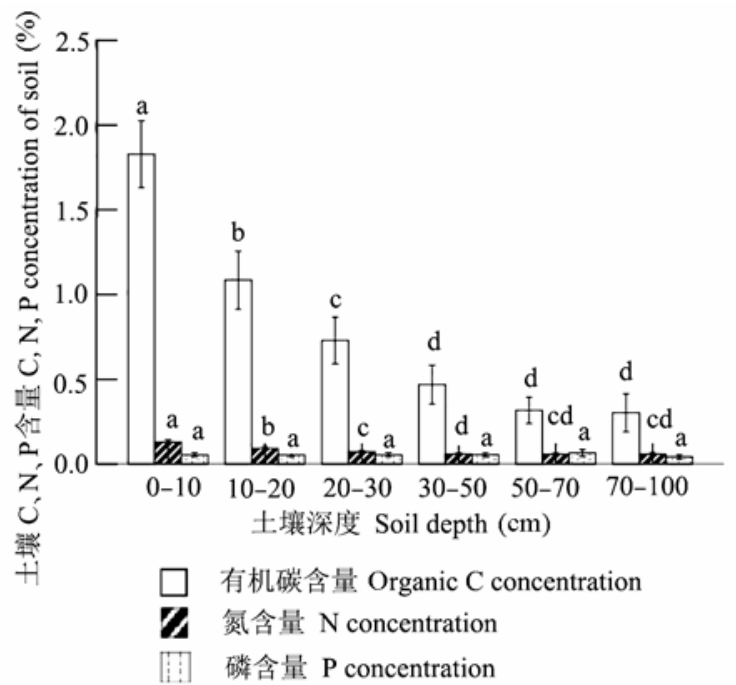

图2 土壤C、N、P含量(平均值土标准偏差)。不同小写字母 表示差异显著 $(p<0.05)$ 。

Fig. 2 Soil $\mathrm{C}, \mathrm{N}$ and $\mathrm{P}$ concentration (mean $\pm S D$ ). Different lowercase letters indicate significant differences $(p<0.05)$.
的P含量与土壤的C、 N、P含量极显著正相关 $(p<$ 0.01 ), 回归系数分别为 $0.007 、 0.114 、 0.191$; 叶的 C 含量则与土壤的 $\mathrm{P}$ 含量极显著负相关 $(p<0.01)$, 回 归系数为 -7.651 (表5)。

\section{3 讨论}

(1)云南杨梅的C、N、P含量均在植物正常范围 (Marschner, 1995)内。云南杨梅的 $\mathrm{C}: \mathrm{N}: \mathrm{P}$ 在根中为 1 531:18:1, 在茎中为1 544:19:1, 在叶中为 818:10:1, 并且，叶的C、N、P含量显著高于其他部位，证明了 营养元素在云南杨梅负责不同功能的部位之间具有 明显不同的分配规律(元素计量特征)。叶是绿色植 物光合作用和呼吸作用的主要部位, 叶中 $\mathrm{N} 、 \mathrm{P}$ 元素 含量较高与其活跃的同化功能有关, 而叶中高浓度 C同样与其生理功能相关。与韩文轩等(2009)的研究 对比发现, 云南杨梅叶的C含量的平均值(49.05\%) 
表5 土壤 $\mathrm{C} 、 \mathrm{~N} 、 \mathrm{P}$ 含量与云南杨梅 $\mathrm{C} 、 \mathrm{~N} 、 \mathrm{P}$ 含量的相关性

Table 5 Correlation between soil and Myrica nana carbon (C), nitrogen (N) and phosphorus (P) concentrations

\begin{tabular}{|c|c|c|c|c|c|c|c|c|c|}
\hline \multirow{2}{*}{$\begin{array}{l}\text { 表层土元素 } \\
\text { Element } \\
\text { in top soil }\end{array}$} & \multicolumn{3}{|c|}{ 根 Root } & \multicolumn{3}{|c|}{ 茎 Stem } & \multicolumn{3}{|c|}{ 叶 Leaf } \\
\hline & C & $\mathrm{N}$ & $P$ & C & $\mathrm{N}$ & $\mathrm{P}$ & C & $\mathrm{N}$ & $\mathrm{P}$ \\
\hline $\mathrm{C}$ & -0.09 & 0.10 & 0.14 & $-0.25^{*}$ & -0.11 & 0.10 & -0.07 & 0.16 & $0.29^{* * *}$ \\
\hline $\mathrm{N}$ & -0.16 & 0.15 & 0.16 & $-0.29^{* *}$ & -0.02 & 0.16 & -0.17 & 0.18 & $0.31^{* *}$ \\
\hline $\mathrm{P}$ & $-0.27^{*}$ & $0.33^{* *}$ & $0.32^{* *}$ & $-0.39^{* *}$ & 0.07 & $0.57^{* *}$ & $-0.39^{* *}$ & 0.21 & $0.46^{* *}$ \\
\hline
\end{tabular}

*, $p<0.05 ;{ }^{* *}, p<0.01$ 。

高于北京及周边地区灌木叶的 C含量平均值 (47.20\%), 而叶的 $\mathrm{N}$ 含量的平均值(1.70\%)和 $\mathrm{P}$ 含量 的平均值 $(0.06 \%)$ 小于北京及周边地区灌木叶的 $\mathrm{N}$ 含 量的平均值 $(2.48 \%)$ 和P含量的平均值 $(0.16 \%)$ 。本研 究的取样地地处滇中地区, 年平均气温高于 16.4 ${ }^{\circ} \mathrm{C}$, 日照时间长, 且受季风气候影响, 夏秋季降水 量大, 平均值达1 $105 \mathrm{~mm}$ (程建刚和解明恩, 2008), 气温、降水量都高于韩文轩等(2009)的研究区域(气 温: $-1.2-12{ }^{\circ} \mathrm{C}$, 降水量: $558 \mathrm{~mm}$ ), 在光照、降水充 足的条件下云南杨梅得以进行充分的光合作用和快 速的新陈代谢, 促进了植物营养器官的构建, 而快 速构建的茎叶中含有大量木质素和叶绿体, 木质素 的碳含量较高, 叶绿体含有大量的有机质, 这就导 致了云南杨梅C的大量积累(郑帷婕等, 2007)。

与中国灌木植物 $\mathrm{N} 、 \mathrm{P}$ 含量的平均值(Han et al., 2005; He et al., 2008)比较, 云南杨梅的N、P含量也 都小于平均值。由于土壤中 $\mathrm{N}$ 常以有机质的形态出 现, 形态多样，长期的生物进化和环境适应导致植 物在以不同形态 $\mathrm{N}$ 为主的土壤上会形成不同的 $\mathrm{N}$ 吸 收机制和策略(吴鹏飞和马祥庆, 2009), 这种环境原 因带来的物种性状差异造成了云南杨梅的 $\mathrm{N}$ 含量与 其他地区的灌木存在差异。根据形态特征、化石、 花粉记录及基于 $r b c \mathrm{~L}$ 基因的分子研究，杨梅科被认 为是最原始的放线菌结瘤植物(Huguet et al., 2001), 我国有4种杨梅, 其中毛杨梅(Myrica esculeata)、云 南杨梅、杨梅(M. rubra) 3 个种能与Frankia放线菌共 生结瘤固 $\mathrm{N}$ 。但环境条件对云南杨梅的固 $\mathrm{N}$ 结瘤有巨 大的影响。王慧英和黄维南(1992)的实验显示, $25-30{ }^{\circ} \mathrm{C}$ 是杨梅根瘤固 $\mathrm{N}$ 的适宜温度, $30{ }^{\circ} \mathrm{C}$ 时固 $\mathrm{N}$ 活性最高, 低温会抑制杨梅根瘤的固 $\mathrm{N}$ 能力, 温度 过高 $\left(>30{ }^{\circ} \mathrm{C}\right)$ 根瘤的固 $\mathrm{N}$ 活力降低。本实验地区地处 较高海拔, 气温较低, 对云南杨梅的固 $\mathrm{N}$ 能力造成 了影响。同时杨梅属植物虽然分布较广, 耐㾉薄, 在 不同土壤中都能生存, 也能结瘤固 $\mathrm{N}$, 但不同的土 壤质地对其结瘤固 $\mathrm{N}$ 影响较大。吴晓丽和顾小平
(1994)的实验显示, 花坛土有利于杨梅的生长和结 瘤固 $\mathrm{N}$, 其生长量、结瘤量及根瘤固 $\mathrm{N}$ 活性最高, 而 红壤最差, 本实验的实验地点位于 $24^{\circ}-26^{\circ} \mathrm{N}$ 之间 的云南省红壤广泛分布区，这也造成了云南杨梅的 固 $\mathrm{N}$ 能力较低。

通过实验发现云南杨梅的 $\mathrm{P}$ 含量的平均值仅为 中国灌木植物 $\mathrm{P}$ 含量平均值 $(0.11 \%)$ (Han et al., 2005) 的一半左右。首先, 植物 $\mathrm{P}$ 含量主要与土壤类型有 关, 土壤中的 $\mathrm{P}$ 含量特别是有效 $\mathrm{P}$ 含量直接决定了植 物的 $\mathrm{P}$ 含量(耿燕等, 2011)。本实验取样的土壤均为 红壤，红壤中 $\mathrm{P}$ 含量很低，由于其特殊的理化性质 使其中的 $\mathrm{P}$ 更易被固定, 导致对植物 $\mathrm{P}$ 含量有直接影 响的有效 P含量更低(李杰等, 2011; 赵其国等, 2013)。通过实测实验地的土壤全P含量发现，其平 均值仅为 $0.05 \%$, 这是云南杨梅的 $\mathrm{P}$ 含量较低的最主 要原因。其次, 植物中 $\mathrm{N} 、 \mathrm{P}$ 的相互限制也对植物中 的 $\mathrm{N} 、 \mathrm{P}$ 含量有影响。植物叶片干生物量中的 $\mathrm{N}: \mathrm{P}$ 是 一个具有重要生态意义的指标, 一方面可以反映植 被的结构和功能特征, 同时也反映了群落水平的营 养限制状况 (Koerselman \& Meuleman, 1996; Güsewell, 2004; Mcgroddy et al., 2004; Niklas et al., 2005)。木本植物作为一个整体, 当 $\mathrm{N}: P$ 达到 15 时, 植 物对 $N 、 P$ 的吸收达到一个平衡。当植物 $N: P$ 下降到 低于临界比率时, 生境中 $\mathrm{P}$ 过量供给, 植物完全吸 收甚至过量吸收 $\mathrm{P}$, 而不完全吸收 $\mathrm{N}$, 植物生长表现 为 $\mathrm{N}$ 限制。相反, 当 $\mathrm{N}: \mathrm{P}$ 增加到大于临界值时, 植物 往往是P限制的(Han et al., 2013)。不同植物类型的 临界值还有区别, 例如, 陆生植物为10-20 (Güsewell, 2005), 湿地植物为14-16 (Koerselman \& Meuleman, 1996)。Han等(2013)的研究显示, 常绿阔叶植 物的养分限制 N:P临界值为 14.3 , 而固 $\mathrm{N}$ 植物应该更 低, 仅为 8 。此次调查的云南杨梅既是常绿阔叶植物 也是固 $\mathrm{N}$ 植物, 其叶 $\mathrm{N}: \mathrm{P}$ 为 34.2 , 明显大于 14.3 和 8 , 说明 $\mathrm{P}$ 元素是云南杨梅生长的限制因素, 在云南杨 梅的生境中, $\mathrm{N}$ 过量供给, 而 $\mathrm{P}$ 相对不足, 云南杨梅

www.plant-ecology.com 
生长中对 $\mathrm{N}$ 完全吸收, 对 $\mathrm{P}$ 不完全吸收。云南杨梅的 这种营养限制状况也在很大程度上造成了云南杨梅 的P含量较低。

(2) N、P是植物生长的关键营养元素, 对构建植 物体有巨大的影响, 控制着植物的生产力大小, 在 本研究中, 云南杨梅叶片的 $\mathrm{N} 、 \mathrm{P}$ 含量都随生物量的 增加而升高, 这证明了 $\mathrm{N} 、 \mathrm{P}$ 在植物生长过程中提供 营养供给的关键作用, N、P含量的增加促进植物构 建植物体增加植物生物量。同时, $\mathrm{N} 、 \mathrm{P}$ 作为大量元 素不仅对生物体中的生物化学功能极为重要, 还具 有相对较高的内稳性(Sterner \& Elser, 2002), 因此, 在生物量变化中必须被不断补充, 从而保持稳定性, 这也导致了随着生物量的增加, $\mathrm{N} 、 \mathrm{P}$ 含量随之升高。 叶片C含量与生物量的相关关系极显著 $(p<0.01)$, 且随着生物量的增加而降低, 这表明云南杨梅的C 含量对植物茎叶的生长有抑制作用, 这和 $\mathrm{C}$ 的生理 作用有关, C主要参与的是叶的光合作用和蒸腾作 用, 而植物的光合作用和 C积累对植物的新陈代谢 和生长有抑制作用。在本研究中, 叶片 $\mathrm{N}: \mathrm{P}$ 与生物量 的相关关系并不显著, 具体原因还不清楚, 但 $\mathrm{N}$ 在 土壤中的形态相当一部分是有机物, 因此其吸收受 植物与微生物关系的影响, 干扰因素较多(van der Heijden et al., 2008), 而 $\mathrm{P}$ 的吸收如前文所说与土壤 $\mathrm{P}$ 含量和植物根构型有很大的关系, 这种差异也可 能导致了叶片 $\mathrm{N}: \mathrm{P}$ 与生物量的相关关系不显著。

(3)由于植被、调落物和腐殖质对土壤 $\mathrm{C} 、 \mathrm{~N}$ 含 量贡献最大(潘鹏等, 2014), 而这些物质主要影响土 壤表层, 并随着土壤深度的加深而减弱, 所以土壤 表层 $(0-10 \mathrm{~cm})$ 的 $\mathrm{C}$ 含量最大, 随着土层的加深 $\mathrm{C}$ 含 量逐渐降低, $\mathrm{N}$ 在表层土壤中的含量也显著高于其 他土层。而土壤号量与土层深度没有明显的规律 性变化则是因为土壤的 $\mathrm{P}$ 含量主要是与土壤类型、 成土母质等因素有关(赵琼和曾德慧, 2005; 和继军 等, 2010)。植物与土壤作为地球化学循环中的不同 环节, 两者必然存在联系, 植物通过土壤吸收养分, 同时又以调落物的形式将 $\mathrm{C} 、 \mathrm{~N} 、 \mathrm{P}$ 归还土壤, 二者 的元素特征具有一定的相关性。云南杨梅根、茎、 叶的 $\mathrm{P}$ 含量与土壤的 $\mathrm{P}$ 含量极显著正相关 $(p<0.01)$ 是因为植物体内的 $\mathrm{P}$ 绝大部分由根系从土壤中吸收 (耿燕等, 2011), 云南杨梅通过根系吸收土壤中的P, 通过养分传输, 使云南杨梅的地上部分和地下部分 的 $\mathrm{P}$ 含量都与土壤的 $\mathrm{P}$ 含量显著正相关, 说明了云南
杨梅能敏感地反映土壤库的动态, 对土壤 $\mathrm{P}$ 含量的 丰缺有着较好的指示作用(陈嘉茜等, 2014)。而根、 茎、叶的C含量都与土壤的P含量呈负相关关系, 因 为植物根系对土壤养分的吸收利用是土壤速效养分 输出的主要途径, 土壤作为植物生长的主要基质, 其中有机质经过分解源源不断地为植物正常生理活 动提供必要的养分, 使得土壤与植物在养分供应与 需求间通过动态交换达到并维持一个平衡的元素比 (王绍强和于贵瑞, 2008)。同时根、茎、叶的N含量 与土壤的 $\mathrm{N}$ 含量相关性都不明显, 这是因为植物的 $\mathrm{N}$ 含量可能更倾向于是一种物种性状，与土壤养分 无关(丁凡等, 2011)。总之, 以上这些特征都是云南 杨梅为了提高自身对营养成分的吸收利用率和对环 境适应性的表现。

基金项目 中国科学院战略性先导科技专项(XDA050503030201)和国家自然科学基金(31560189)。

致谢 感谢西南林业大学科技创新基金(15110)资助。

\section{参考文献}

Aerts R, Beltman B (2003). Is the relation between nutrient supply and biodiversity co-determined by the type of nutrient limitation? Oikos, 101, 489-498.

Aerts R, Chapin FS III (2000). The mineral nutrition of wild plants revisited: A re-evaluation of processes and patterns. Advances in Ecological Research, 30, 1-67.

Ågren GI (2008). Stoichiometry and nutrition of plant growth in natural communities. Ecology, Evolution, and Systematics, 39, 153-170.

Chen JQ, Zhang LL, Li J, Wen DZ, Peng ST (2014). Carbon, nitrogen and phosphorus stoichiometry of two fern species and their relationships to nutrient availability. Journal of Tropical and Subtropical Botany, 22, 567-575. (in Chinese with English abstract) [陈嘉茜, 张玲玲, 李昫, 温达志, 彭诗涛 (2014). 硕类植物碳氮磷化学计量特征 及其与土壤养分的关系. 热带亚热带植物学报, 22 ,

Cheng JG, Xie ME (2008). The analysis of regional climate change features over Yunnan in recent 50 years. Progress in Geography, 27, 19-26. (in Chinese with English abstract) [程建刚, 解明恩 (2008). 近50年云南区域气 候变化特征分析. 地理科学进展, 27, 19-26.]

Diemer M (2004). The worldwide leaf economics spectrum. Nature, 428, 821-827.

Ding F, Lian PY, Zeng DH (2011). Characteristics of plant leaf nitrogen and phosphorus stoichiometry in relation to soil nitrogen and phosphorus concentrations in Songnen Plain meadow. Chinese Journal of Ecology, 30, 77-81. (in Chinese with English abstract) [丁凡, 廉培勇, 曾德慧 
(2011). 松嫩平原草甸三种植物叶片N、P化学计量特征 及其与土壤N、P浓度的关系. 生态学杂志, 30, 77-81.]

Editorial Board of Flora of China, Chinese Academy of Sciences (1979). Flora of China. Vol. 21. Science Press, Beijing. (in Chinese) [中国科学院中国植物志编辑委员 会 (1979). 中国植物志. 第21卷. 科学出版社, 北京.]

Ehleringer JR, Field CB (1993). Scaling Physiological Processes: Leaf to Globe. Academic Press, San Diego,

ElserUAAFagan WF, Denno RF, Dobberfuhl DR, Folarin A, Huberty A, Interlandi S, Kilham SS, McCauley E, Schulz KL (2000a). Nutritional constraints in terrestrial and freshwater food webs. Nature, 408, 578-580.

Elser JJ, Fagan WF, Kerkhoff AJ, Swenson NG, Enquist BJ (2010). Biological stoichiometry of plant production: Metabolism, scaling and ecological response to global change. New Phytologist, 186, 593-608.

Elser JJ, Sterner RW, Gorokhova E, Fagan WF, Markow TA, Cotner JB, Harrison JF, Hobbie SE, Odell GM, Weider LW (2000b). Biological stoichiometry from genes to ecosystems. Ecology Letters, 3, 540-550.

Geng Y, Wu Y, He JS (2011). Relationship between leaf phosphorus concentration and soil phosphorus availability across Inner Mongolia grassland. Chinese Journal of Plant Ecology, 35, 1-8. (in Chinese with English abstract) [耿 燕, 吴渏, 贺金生 (2011). 内蒙古草地叶片磷含量与土 壤有效磷的关系. 植物生态学报, 35, 1-8.]

Gong HD, Cheng XP, Ma YW (2012). Characteristics of biomass distribution in Myrica nana. Nonwood Forest Research, 30(4), 106-108. (in Chinese with English abstract) [巩合德, 程希平, 马月伟 (2012). 云南杨梅灌 丛生物量的分配特征. 经济林研究, 30(4), 106-108.]

Güsewell S (2004). N:P ratios in terrestrial plants: Variation and functional significance. New Phytologist, 164, 243-266.

Güsewell S (2005). Nutrient resorption of wetland graminoids is related to the type of nutrient limitation. Functional Ecology, 19, 344-354.

Güsewell S, Bailey KM, Roem WJ, Bedford BL (2005). Nutrient limitation and botanical diversity in wetlands: Can fertilization raise species richness? Oikos, 109, 71-80.

Han WX, Fang JY, Guo DL, Zhang Y (2005). Leaf nitrogen and phosphorus stoichiometry across 753 terrestrial plant species in China. New Phytologist, 168, 377-385.

Han WX, Tang LY, Chen YH, Fang JY (2013). Relationship between the relative limitation and resorption efficiency of nitrogen $v$ s phosphorus in woody plants. PLOS ONE, 8, e83366. doi: 10.1371/journal.pone.0083366.

Han WX, Wu Q, Tang LY, Chen YH, Li LP, He JS, Fang JY (2009). Leaf carbon, nitrogen and phosphorus stoichiometry across plant species in Beijing and its periphery. Acta Scientiarum Naturalium Universitatis Pekinensi, 45, 855-860. (in Chinese with English abstract) [韩文轩, 吴 渏, 汤璐瑛, 陈雅涵, 李利平, 贺金生, 方精云 (2009).
北京及周边地区植物叶的碳氮磷元素计量特征. 北京 大学学报(自然科学版), 45, 855-860.]

Harpole WS, Ngai JT, Cleland EE, Seabloom EW, Borer ET, Bracken MES, Elser JJ, Gruner DS, Hillebrand H, Shurin JB, Smith JE (2011). Nutrient co-limitation of primary producer communities. Ecology Letters, 14, 852-862.

He JJ, Cai GQ, Tian L, Fang HY (2010). Effect of vegetation measures on the soil conservation and factors analysis. Chinese Journal of Soil Science, 41, 706-710. (in Chinese with English abstract) [和继军, 蔡国强, 田否, 方海燕 (2010). 植被措施对土壤保育的作用及其影响因素分析. 土壤通报, 41, 706-710.]

He JS, Wang L, Flynn DF, Wang XP, Ma WH, Fang JY (2008). Leaf nitrogen:phosphorus stoichiometry across Chinese grassland biomes. Oecologia, 155, 301-310.

Hong JT, Wu JB, Wang XD (2013). Effects of global climate change on the $\mathrm{C}, \mathrm{N}$, and $\mathrm{P}$ stoichiometry of terrestrial plants. Chinese Journal of Applied Ecology, 24, 2658-2665. (in Chinese with English abstract) [洪江涛, 吴建波, 王小 丹 (2013). 全球气候变化对陆地植物碳氮磷生态化学 计量学特征的影响. 应用生态学报, 24, 2658-2665.]

Hou XY (1982). Chinese Vegetation Geology and Chemical Content of Dominant Plants. Science Press, Beijing. (in Chinese) [侯学煜 (1982). 中国植被地理及优势植物化 学成分. 科学出版社, 北京.]

Huguet V, Batzli JM, Zimpfer JF, Normand P, Dawson JO, Fernandez MP (2001). Diversity and specificity of Frankia strains in nodules of sympatric Myrica gale, Alnus incana, and Shepherdia canadensis determined by rrs gene polymorphism. Applied and Environmental Microbiology, 67, 2116-2122.

Jackson RB, Banner JL, Jobbágy EG, Pockman WT, Wall DH (2002). Ecosystem carbon loss with woody plant invasion of grasslands. Nature, 418, 623-626.

Koerselman W, Meuleman AFM (1996). The vegetation N:P ratio: A new tool to detect the nature of nutrient limitation. Journal of Applied Ecology, 33, 1441-1450.

Li J, Shi YL, Chen ZW (2011). Research on phosphorus in southern red soils of in China. Chinese Journal of Soil Science, 42, 763-768. (in Chinese with English abstract) [李杰, 石元亮, 陈智文 (2011). 我国南方红壤磷素研 究概况. 土壤通报, 42, 763-768.]

Liu GH, Ma KM, Fu BJ, Guan WB, Kang YX, Zhou JY, Liu SL (2003). Above ground biomass of main shrubs in dry valley of Minjing river. Acta Ecologica Sinica, 23, 1757-1764. (in Chinese with English abstract) [刘国华, 马克明, 傅伯杰, 关文涁, 康永祥, 周建云, 刘世梁 (2003). 岷江干旱河谷主要灌丛类型地上生物量研究. 生态学报, 23, 1757-1764.]

Marschner H (1995). Mineral Nutrition of Higher Plants. Academic Press, New York.

www.plant-ecology.com 
Mcgroddy ME, Daufresne T, Hedin LO (2004). Scaling of $\mathrm{C}: \mathrm{N}: \mathrm{P}$ stoichiometry in forests worldwide: Implications of terrestrial Redfield-type ratios. Ecology, 85, 2390-2401.

Niklas KJ, Owens T, Reich P, Cobb ED (2005). Nitrogen/ phosphorus leaf stoichiometry and the scaling of plant growth. Ecology Letters, 8, 636-642.

Niu DC, Li Q, Jiang SG, Chang PJ, Fu H (2013). Seasonal variations of leaf C:N:P stoichiometry of six shrubs in desert of China's Alxa Plateau. Chinese Journal of Plant Ecology, 37, 317-325. (in Chinese with English abstract) [牛得草, 李茜, 江世高, 常佩静, 傅华 (2013). 阿拉善 荒漠区6种主要灌木植物叶片 C:N:P化学计量比的季节 变化. 植物生态学报, 37, 317-325.]

Pan J, Song NP, Wu XD, Yang XG, Chen L, Qu WJ (2015). Effects of different planting-years of artificial Caragana intermedia shrubs on soil organic carbon, nitrogen and phosphorus stoichiometry characteristics in desert steppe. Journal of Zhejiang University (Agriculture \& Life Sciences), 41, 160-168. (in Chinese with English abstract) [潘军, 宋乃平, 吴旭东, 杨新国, 陈林, 曲文杰 (2015). 荒漠草原不同种植年限人工柠条林土壤碳氮磷化学计 量特征. 浙江大学学报 (农业与生命科学版), 41 , 160-168.]

Pan P, Gan WF, Ouyang XZ, Xiao X (2014). Relationship between the contents of soil organic carbon, total nitrogen, total phosphorus and soil organic carbon density of Pinus massoniana nature forest. Journal of Northwest Forest University, 29(6), 1-5. (in Chinese with English abstract) [潘鹏, 甘文峰, 欧阳勋志, 肖欣 (2014). 马尾松天然林 土壤碳氮磷含量与碳密度的关系. 西北林学院学报, 29(6), 1-5.]

Ren SJ, Yu GR, Jiang CM, Fang HJ, Sun XM (2012). Stoichiometric characteristics of leaf carbon, nitrogen, and phosphorus of 102 dominant species in forest ecosystems along the North-South Transect of East China. Chinese Journal of Applied Ecology, 23, 119-124. (in Chinese with English abstract) [任书杰, 于贵瑞, 姜春明, 方华军, 孙 晓敏 (2012). 中国东部南北样带森林生态系统102个优 势种叶片碳氮磷化学计量学统计特征. 应用生态学报, 23, 119-124.]

Shao XX, Li WH, Wu M, Yang WY, Jiang KY, Ye XQ (2013). Dynamics of carbon, nitrogen and phosphorus storage of three dominant marsh plants in Hangzhou Bay coastal wetland. Environmental Science, 4, 3451-3457. (in Chinese with English abstract) [邵学新, 李文华, 吴明, 杨文 英, 蒋科毅, 叶小齐 (2013). 杭州湾潮滩湿地3种优势 植物碳氮磷储量特征研究. 环境科学, 4, 3451-3457.]

Sterner RW, Elser JJ (2002). Ecological Stoichiometry: The Biology of Elements from Molecules to the Biosphere. Princeton University Press, Princeton.

Sturm M, Racine CH, Tape KD (2001). Increasing shrub abun- dance in the arctic. Nature, 411, 546-547.

van de Waal DB, Verschoor AM, Verspagen JMH, van Donk

E, Huisman J (2010). Climate-driven changes in the ecological stoichiometry of aquatic ecosystems. Frontiers in Ecology \& the Environment, 8, 145-152.

van der Heijden MGA, Bardgett RD, van Straalen NM (2008). The unseen majority: Soil microbes as drivers of plant diversity and productivity in terrestrial ecosystems. Ecology Letters, 11, 296-310.

Venterink HO, Wassen MJ, Verkroost AWM, de Ruiter PC (2003). Species richness-productivity patterns differ between N-, P-, and K-limited wetlands. Ecology, 84, 21912199.

Vitousek PM (1982). Nutrient cycling and nutrient use efficiency. American Naturalist, 119, 553-573.

Vitousek PM, Farrington H (1997). Nutrient limitation and soil development: Experimental test of a biogeochemical theory. Biogeochemistry, 37, 63-75.

von Oheimb G, Power SA, Falk K, Friedrich U, Mohamed A, Krug A, Boschatzke N, Härdtle W (2010). N:P ratio and the nature of nutrient limitation in Calluna-dominated heathlands. Ecosystems, 13, 317-327.

Wang HY, Huang WN (1992). Characteristics of symbiotic nitrogen fixation by Myrica rubra. Fujian Journal of Agricultural Science, 7(2), 48-52. (in Chinese with English abstract) [王慧英, 黄维南 (1992). 杨梅根瘤的 共生固氮特性. 福建农业学报, 7(2), 48-52.]

Wang JY, Wang SQ, Li RL, Yan JH, Sha LQ, Han SJ (2011). $\mathrm{C}: \mathrm{N}: \mathrm{P}$ stoichiometric characteristics of four forest types' dominant tree species in China. Chinese Journal of Plant Ecology, 35, 587-595. (in Chinese with English abstract) [王晶苑, 王绍强, 李㧅兰, 间俊华, 沙丽清, 韩士杰 (2011). 中国四种森林类型主要优势植物的C:N:P化学 计量学特征. 植物生态学报, 35, 587-595.]

Wang SQ, Yu GR (2008). Ecological stoichiometry characteristics of ecosystem carbon, nitrogen and phosphorus elements. Acta Ecologica Sinica, 8, 3937-3947. (in Chinese with English abstract) [王绍强, 于贵瑞 (2008). 生态系统碳氮磷元素的生态化学计量学特征. 生态学 报, 8, 3937-3947.]

Wright IJ, Reich PB, Westoby M (2001). Strategy shifts in leaf physiology, structure and nutrient content between species of high- and low-rainfall and high- and low-nutrient habitats. Functional Ecology, 15, 423-434.

Wu PF, Ma QX (2009). Research advances in the mechanisms of high nutrient use efficiency in plants. Acta Ecologica Sinica, 29, 427-437. (in Chinese with English abstract) [ 吴 鹏飞, 马祥庆 (2009). 植物养分高效利用机制研究进 展. 生态学报, 29, 427-437.]

Wu XL, Gu XP (1994). A study on the characteristics of Myrica rubra in nodulation and nitrogen fixation. Forest Research, 3, 306-310. (in Chinese with English abstract) 
[吴晓丽, 顾小平 (1994). 杨梅结瘤固氮特性研究. 林 业科学研究, 3, 306-310.]

Xie HT, He XD, You WX, Yu D, Liu HF, Wang JL, Gu S, Nie QH, Liang YT, Zhang JL (2016). Effects of ecological stoichiometry on biomass and species diversity of the Artemisia ordosica community in Habahu National Nature Reserve. Acta Ecologica Sinica, 36, 3621-3627. (in Chinese with English abstract) [颕洪涛, 何兴东, 尤万学, 余殿, 刘惠芬, 王金龙, 古松, 聂庆华, 梁玉婷, 张京否 (2016). 哈巴湖国家级自然保护区油蒿群落生态化学计 量特征对群落生物量和物种多样性的影响. 生态学报, 36, 3621-3627.]

Yan BG, Liu GC, Fan B, He GX, Shi LT, Li JC, Ji ZH (2015). Relationships between plant stoichiometry and biomass in an arid-hot valley, Southwest China. Chinese Journal of Plant Ecology, 39, 807-815. (in Chinese with English abstract) [间帮国, 刘刚才, 㚞博, 何光熊, 史亮涛, 李 纪潮, 纪中华 (2015). 干热河谷植物化学计量特征与生 物量之间的关系. 植物生态学报, 39, 807-815.]

Yan ZB, Kim NY, Han TS, Fang JY, Han WY (2013). Effects of nitrogen and phosphorus fertilization on leaf carbon, nitrogen and phosphorus stoichiometry of Arabidopsis thaliana. Chinese Journal of Plant Ecology, 37, 551-557. (in Chinese with English abstract) [严正兵, 金南瑛, 韩廷 申, 方精云, 韩文轩 (2013). 氮磷施肥对拟南芥叶片碳 氮磷化学计量特征的影响. 植物生态学报, 37, 551-557.]

Yin XR, Liang CZ, Wang LX, Wang W, Liu ZL, Liu XP (2010). Ecological stoichiometry of plant nutrients at different restoration succession stages in typical steppe of Inner Mongolia, China. Chinese Journal of Plant Ecology, 34, 39-47. (in Chinese with English abstract) [银晓瑞, 梁 存柱, 王立新, 王炜, 刘钟龄, 刘小平 (2010). 内蒙古 典型草原不同恢复演替阶段植物养分化学计量学. 植 物生态学报, 34, 39-47.]

Zeng DH, Chen GS (2005). Ecological stoichiometry: A sci- ence to explore the complexity of living systems. Acta Phytoecologica Sinica, 29, 1007-1019. (in Chinese with English abstract) [曾德慧, 陈广生 (2005). 生态化学计 量学: 复杂生命系统奥秘的探索. 植物生态学报, 29, 1007-1019.]

Zhang WY, Fan JW, Zhong HP, Hu ZM, Song LL, Wang N (2010). The nitrogen:phosphorus stoichiometry of different plant functional groups for dominant species of typical steppes in China. Acta Agrestia Sinica, 18, 503-509. (in Chinese with English abstract) [张文彦, 禁 江文, 钟华平, 胡中民, 宋璐璐, 王宁 (2010). 中国典 型草原优势植物功能群氮磷化学计量学特征研究. 草 地学报, 18, 503-509.]

Zhao Q, Zeng DH (2005). Phosphorus cycling in terrestrial ecosystems and its controlling factors. Acta Phytoecologica Sinica, 29, 153-163. (in Chinese with English abstract) [赵琼, 曾德慧 (2005). 陆地生态系统磷素循 环及其影响因素. 植物生态学报, 29, 153-163.]

Zhao QG, Huang GQ, Ma YQ (2013). The problems in red soil ecosystem in southern of China and its countermeasures. Acta Ecologica Sinica, 33, 7615-7622. (in Chinese with English abstract) [赵其国, 黄国勤, 马艳芹 (2013). 中 国南方红壤生态系统面临的问题及对策. 生态学报, 33, 7615-7622.]

Zheng S, Shangguan Z (2007). Spatial patterns of leaf nutrient traits of the plants in the Loess Plateau of China. Trees, 21, 357-370.

Zheng WJ, Bao WK, Gu B, He X, Leng L (2007). Carbon concentration and its characteristics in terrestrial higher plant. Chinese Journal of Ecology, 26, 307-313. (in Chinese with English abstract) [郑帷婕, 包维楷, 喜涁, 何晓, 冷俐 (2007). 陆生高等植物碳含量及其特点. 生 态学杂志, 26, 307-313.]

责任编委: 唐志尧 责任编辑: 李 敏

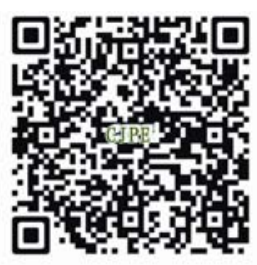

植物生态学报官网

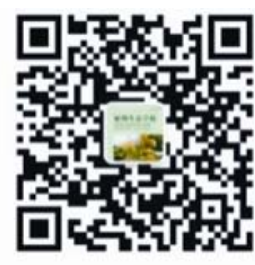

微信订阅号 期刊及学科 相关信息发布

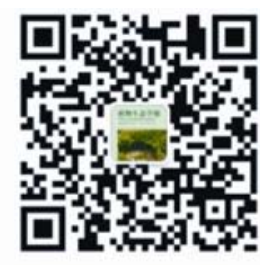

微信服务号

稿件状态查询

全文检索浏览 